\title{
La libertad religiosa en Europa. Una clasificación según la relación entre los Estados y las Iglesias.
}

\author{
Diego Aboy Rubio ${ }^{1}$
}

\begin{tabular}{ll}
\hline INFORMACIÓN DEL ARTÍCULO & RESUMEN \\
\hline Historia del artículo: & La libertad religiosa es derecho reconocido en todos los estados europeos. \\
Recibido el 23 junio de 2011 & Pero Europa Occidental no es un continente religiosamente monocolor ni en el \\
Aceptado el 15 de julio de 2011 & plano de la fe ni en la praxis. La cultura europea procede de una misma raíz \\
& cristiana que a lo largo del tiempo se ha articulado en tres grandes formas: \\
\hline Palabras claves: & católica, protestante y ortodoxa. En este estudio se expone una clasificación de \\
Libertad Religiosa & algunos Estados según su relación con las Iglesias o confesiones. \\
Estados Europeos &
\end{tabular}

Iglesia

Confesiones

\section{Religious freedom in Europe}

A classification according to the relationship between the States and the Churches

\section{Introducción}

El reconocimiento de la libertad religiosa aparece en las constituciones de la mayoría de los estados europeos. Así la italiana en su art. 19²; la española en el art.16; también la de Irlanda, art. $44^{3}$. En Alemania La Ley fundamental garantiza en el art. 4, el libre ejercicio del culto ${ }^{4}$.

La mayoría de las constituciones han integrado el art. 9 del Convenio Europeo de Derechos Humanos afirma la libertad religiosa pero no reconoce expresamente el derecho a los lugares de culto, y tampoco lo hace el art.10 de la Carta de Derechos Fundamentales de la Unión Europea.
Pero Europa Occidental no es un continente religiosamente monocolor ni en el plano de la fe ni en la praxis. La cultura europea procede de una misma raíz cristiana que a lo largo del tiempo se ha articulado en tres grandes formas: católica, protestante y ortodoxa. Junto a esta base hay que tener en cuenta la Ilustración, el lusnaturalismo racionalista y la doctrina sobre los Derechos Humanos.

Es por ello que se puede clasificar las relaciones entre los estados europeos y las confesiones religiosas en tres grandes bloques: estados confesionales o de confesión dominante; estados de inspiración laicista; y estados

\footnotetext{
${ }^{1}$ Doctor en Derecho Canónico por la Universidad de Navarra. Pamplona, España. Abogado Rotal. Profesor Visitante de la Facultad de Derecho de la Universidad Católica Santo Toribio de Mogrovejo.

${ }^{2}$ Artículo 19 «Todos tendrán derecho a profesar libremente su propia fe religiosa en cualquier forma, individual o asociada, hacer propaganda de la misma y practicar el culto respectivo en privado o en público, con tal de que no se trate de ritos contrarios a las buenas costumbres».

${ }^{3}$ Artículo 44 «1. El Estado reconoce que se debe el tributo de culto público a Dios Todopoderoso, cuyo nombre reverenciara, y respeta y honra la religión. 2. 10. Dentro de las exigencias del orden público y de la moral se garantizan a todos los ciudadanos la libertad de conciencia y la libre profesión y práctica de la religión.(...)»

${ }^{4}$ Artículo 4 «La libertad de creencia y de conciencia y la libertad de confesión religiosa e ideológica son inviolables. Se garantizará el libre ejercicio del culto. Nadie podrá ser obligado, contra su conciencia, a realizar el servicio militar con armas. La regulación se hará por una ley federal».
} 
inspirados en el principio de cooperación religiosa ${ }^{5}$. La confesionalidad se mantiene en el mundo anglicano, luterano y en la ortodoxia (Inglaterra, Escocia, Dinamarca, Finlandia, Grecia); en Francia, el sistema es de separación laicista; y, por último, Alemania, España e Italia siguen un sistema de cooperación. Tales diferencias no son meramente teóricas sino que se reflejan en la legislación interna de cada país ${ }^{6}$.

\section{SISTEMA CONFESIONAL: LAS IGLESIAS NACIONALES}

Las iglesias nacionales son fruto de la ruptura entre la iglesia de Oriente y Occidente (la griega), de la Reforma (nórdicas) o del conflicto entre el Príncipe y el Papa (anglicana). Este sistema se caracteriza por la ausencia de la autonomía de las confesiones y por el papel predominante del Estado. La iglesia oficial está sometida al Estado y depende en gran medida del poder civil. En estos países existe la libertad religiosa pero para las confesiones no oficiales es menor.

\subsection{El caso del Reino Unido}

En el Reino Unido la realidad de las iglesias, confesiones y religiones es compleja. Hay dos iglesias oficiales la iglesia de Inglaterra y la iglesia de Escocia (de estructura presbiteral), en el país de Gales e Irlanda del norte no hay iglesia oficial. Por otra parte están las Free Churches (Metodistas, Baptistas Ejército de Salvación...) que agrupan a las comunidades protestantes, la iglesia católica romana y otras ramas cristianas, tanto las iglesias de oriente (ortodoxos, armenios, coptos) como luteranos e iglesias reformadas de varios países europeos y grupos religiosos fundados en Estados unidos. Además existen comunidades budistas, hindú, judías, musulmanas y sikh. Esta pluralidad religiosa no es sinónimo de una convivencia armónica, en muchos casos las minorías religiosas no se sienten británicos, ni representados por la jerarquía anglicana presente en la Cámara de los Lores?

No es posible hallar en sus textos constitucionales, ninguna declaración de libertad religiosa. Se puede considerar que se sobrentiende de tal modo que

\footnotetext{
${ }^{5}$ Cfr. SOUTO PAZ, J.A., Comunidad política y libertad de creencias, Madrid, Marcial Pons, 1999, p. 219.

${ }^{6}$ Cfr. DE LA HERA, A., "La libertad religiosa en Europa Occidental", en luri canonico quo sit Christi ecclesia felix: estudios canónicos en homenaje al prof. Dr. D. Julio Manzanares Marijuán, Salamanca 2002, p. 595.

7 GARCÍA OLIVA, J., Compatibilidad del pluralismo religioso en Inglaterra con el modelo confesional del país, en Derecho de familia y libertad de conciencia en los países de la Unión Europea y el derecho comparado: actas del IX Congreso Internacional de Derecho Eclesiástico del Estado, San Sebastián 2001, pp. 491-498.
}

cualquier acto que la conculcase sería enérgicamente rechazado. La libertad religiosa está garantizada aunque no tiene un reconocimiento expreso ${ }^{8}$. La relación entre el Estado y la iglesia oficial es constitucional, es decir el establishment supone que el Estado acepta como la expresión de la fe cristiana a una Iglesia establecida, este reconocimiento político exige por parte del Estado el deber legal de proteger, preservar y defender la confesión oficial. En consecuencia esto excluye al resto de las confesiones y otorga a la iglesia oficial unos derechos y beneficios propios de su posición. La iglesia establecida forma parte del organigrama estatal es instrumento de los poderes públicos y está sujeta a las restricciones y deberes que tal estatus le reporta ${ }^{9}$. La Iglesia de Inglaterra está sujeta a un conjunto de normas jurídicas, estatutarias en su mayoría, que gobiernan sus instituciones, estructuras territoriales, administrativas y sus propiedades, y que requiere autorización parlamentaria ${ }^{10}$. El Rey es el guardián de todas las formas de Justicia, en su coronación se obliga a al cuidado del Evangelio y de la religión protestante establecida en by law. El monarca es el primer laico investido de un carácter sagrado, es la principal institución eclesiástica en el Reino Unido. Es necesario el asentimiento del Soberano en el Parlamento de las medidas aprobadas en el Sínodo de la Iglesia Inglaterra. Las distintas iglesias a la anglicana, y las otras religiones son consideradas como asociaciones voluntarias. Su derecho propio es un mero contrato entre las partes y en el caso de iglesias más complejas se suele emplear un Acta privada del Parlamento. Las organizaciones religiosas son consideradas como entidades de tipo caritativo, así sus edificios está exentos de impuestos directos y de tasas locales. Por otra parte los lugares de culto suelen acceder al registro como sede para celebrar matrimonios ${ }^{11}$.

Los asuntos sobre la propiedad se abordan por medio de trust, no existe una norma que establezca los criterios para determinar si una entidad concreta es una iglesia o no. Por lo que la jurisprudencia es la que valora en cada caso ${ }^{12}$. La Court of Appeal para registrar un edificio como lugar de culto exigió que hubiera una

\footnotetext{
8 LÓPEZ LOZANO, C., "Modelo actual de Estado Confesional”, en Anuario de Derecho Eclesiástico del Estado", 24 (2008) p. 25.

${ }^{9}$ GARCÍA OLIVA, J., "Consideraciones sobre la Iglesia de Inglaterra y su relación con el Estado", en Anuario de Derecho Eclesiástico del Estado, 17 (2001) pp. 311-374.

${ }^{10}$ Church n State. Sport of the Archbishops'Commission, 1970, p.1.

11 Paces of Worship Registration, Act de 1855.

12 MC CLEAN, D., "Estado e Iglesia en el Reino Unido", en ROBBERS G., (ed.), Estado e Iglesia en la Unión

Europea., Baden-Baden, Nomos Verlagsgesellschaf ,1996, p. 316.
} 
asamblea de personas unidas para dar culto a Dios o un ser supremo, por lo que se rechazó la petición de la iglesia de la Cienciología. En cambio, en el caso del Budismo, se hizo una excepción pues aunque es una religión no está claro que sus creencias impliquen un Ser Supremo ${ }^{13}$.

\subsection{Dinamarca}

La Constitución danesa de 1953, en el art. 4, establece: «la Iglesia evangélica luterana es la Iglesia oficial de Dinamarca y, como tal, es subvencionada por el Estado». El rey debe pertenecer a ella. Por otra parte, el art. 68 dispone que «nadie puede ser obligado a realizar contribuciones personales a ninguna confesión que no sea la suya». El art. 67 garantiza a los ciudadanos el derecho a «formar comunidades de fieles para el culto a Dios de acuerdo con sus convicciones, siempre y cuando no se enseñe o haga nada contrario a la buena moral y el orden público». El art. 70 establece que «ninguna persona será privada del pleno disfrute de sus derechos cívicos y políticos por razón de su fe u origen, ni quedará exenta de ningún deber cívico por dichas razones», al tiempo que el art. 71 señala: «La libertad personal es inviolable. Ningún ciudadano danés [...] puede ser privado de su libertad por sus convicciones políticas o religiosas, o por su origen».

No existe una ley específica que regule las otras confesiones o comunidades religiosas disidentes (así las llamaba la constitución de 1849). Existen una serie de normas sobre la no discriminación por motivos religiosos en el Código penal y en la legislación administrativa. En 1992 Dinamarca se ratificó el Convenio Europeo de Derechos Humanos incorporando el principio de la libertad religiosa en el ordenamiento jurídico danés.

No hay concepto de iglesia, se puede considerar que la iglesia nacional es un organismo estatal de la administración central sin personalidad jurídica. Las parroquias son organismo estatales de la administración central y cumple funciones administrativas. La iglesia nacional está formada por unas 2100 parroquias electivas que forman la unidad democrática fundamental de la iglesia nacional Danesa. Éstas han de tener un comité o consejo de dirección con capacidad legal para obligarse y debe disponer de su propia iglesia o salón parroquial adecuado. Existen además las parroquias indepen-dientes que quieren ser autónomas de la organización de la iglesia nacional.

El Ministerio de Asuntos Religiosos reconoce a las demás confesiones por medio de un Real Decreto. Son

\footnotetext{
${ }^{13}$ Barralet v Attorny-General, 1980, 3 All ER 918.
}

instituciones privadas autónomas sometidas a la legislación de asociaciones privadas danesa cuando adquieren inmuebles o fundan centros benéficos o educativos. Las confesiones reconocidas pueden celebrar bautismos, matrimonio, y defunciones con eficacia civil. Por otra parte, un ministro de una confesión no reconocida puede recibir autorización personal del Ministerio de Asuntos Eclesiásticos para celebrar matrimonios con eficacia civil.

Oficialmente están reconocidas la Iglesia católica, la comunidad hebrea, la comunidad islámica, la Iglesia metodista, la comunidad baptista, la Iglesia rusoortodoxa y a más de un centenar de otras confesiones $^{14}$.

\subsection{Malta}

La Constitución de 1964, en el art. 2.1, establece que la Iglesia católica, apostólica y romana es la Iglesia oficial de Malta. Además, las autoridades de la Iglesia católica tienen «el derecho y la obligación de enseñar qué principios son justos y cuáles, equivocados» (art. 2.2). El art. 2.3 establece que en la escuela pública debe impartirse la asignatura de Religión Católica Apostólica y Romana como parte del plan de estudios obligatorio, si bien cabe la posibilidad de exoneración.

Por otra parte el art. 32 garantiza a todos los ciudadanos los derechos y libertades individuales fundamentales, sin discriminación por razón de raza, origen, opiniones políticas, color, credo o sexo, siempre y cuando se respete el interés público. Tales derechos incluyen de forma expresa el derecho a «la vida, la libertad, la seguridad, la propiedad y la protección legal, la libertad de conciencia, expresión y reunión, así como de asociación pacífica y el derecho al respeto de la vida privada y familiar».

Todas las organizaciones religiosas tienen los mismos derechos y pueden organizarse según su propio derecho. Pueden tener sus propios edificios que habitualmente lo hacen por medio del sistema de trust.

\subsection{Grecia}

En Grecia, la constitución vigente de 1975 recoge en el art. 3 que la confesión ortodoxa es la religión dominante. Por otra parte, el art. 13 reconoce la libertad de conciencia y de culto que no puede ir en contra del orden público ni de las buenas costumbres. En su párrafo segundo protege a todas las religiones del proselitismo, éste es un delito castigado con penas de privación de libertad y multas.

14 DÜBECK, I., "Estado e Iglesia en Dinamarca”, En ROBBERS G. (ed.), Estado (...) Ob. cit., pp. 37-56. 
La erección de edificios de culto (iglesias, casas de oración, sinagogas, mezquitas) necesita la licencia del Ministerio de educación y cultos. Asimismo, se debe contar con la opinión del metropolita ortodoxo del lugar ${ }^{15}$ (art. 41. de la ley de medidas urgentes, $n$. 1369/1938). Esta no es vinculante para el Ministerio, pero la autorización debe estar fundada específicamente cuando el metropolita se opone, que es lo habitual. En el caso de que sea denegada la licencia los interesados pueden apelar al Consejo de Estado, que en la mayoría de los casos concede el permiso solicitado ${ }^{16}$. De tal modo que la obtención del permiso para la construcción de los lugares de culto es un proceso bastante lento ${ }^{17}$.

La práctica política procura favorecer la libertad religiosa y la igualdad a pesar de la normativa, que privilegia a la iglesia ortodoxa ${ }^{18}$. En el 2007, el Gobierno aprobó una enmienda a la ley existente, derogando la práctica de solicitar permiso a los obispos grecoortodoxos locales antes de erigir lugares de culto de otras religiones ${ }^{19}$.

\section{EL SISTEMA DE SEPARACIÓN}

\subsection{Francia ${ }^{20}$}

La actual constitución francesa de 1958 garantiza la igualdad de todos los ciudadanos ante la ley sin distinción de origen, de raza o de religión. La República respeta todas las creencias (art. 2). El principio de libre ejercicio de los cultos es prolongación de la libertad de conciencia. El estado no tiene religión oficial ni dominante, ni cultos reconocidos. La religión es un asunto privado sometido al derecho privado. Además del texto constitucional los principios básicos de la relación entre las iglesias y del estado los podemos encontrar en la Ley de separación de 1905. La ley

\footnotetext{
${ }^{15}$ La primera jurisprudencia del Consejo de Estado consideraba que la licencia del metropolita era un elemento constitucional, ya que era un medio para la protección de la iglesia dominante. La construcción de un templo de otra religión se podía considerar un acto de proselitismo. Cfr. SALACHAS, D., "Diritti fondamentale della persona umnana e la libertà religiosa nella Costituzione della Repubblica ellenica", en Biffi, F., (ed.), I diritti fondamentali della persona umana e la libertà religiosa: Atti del V Colloquio Giuridico (8-10 Marzo 1984), Città del Vaticano, 1985, p. 624.

${ }^{16} \mathrm{Cfr}$. PAPASTATHIS, CH., "Estado e Iglesia en Grecia", En ROBBERS G., (ed.), Estado (...) Ob. cit., p. 83.

${ }^{17}$ Así lo corrobora el Departamento de Estado: «Different groups that follow the ancient polytheistic Hellenic tradition applied in each of the last four years for house-of-prayer permits. (...) The Jehovah's Witnesses had

11 pending house-of-prayer permit requests, some dating from 2005» (U.S. DEPARTAMENT OF STATE,

"Greece», 2008 Report on International Religious Freedom, http://2001-
}

establece un régimen de separación. Se prohíbe la concesión de ayudas públicas a una específica confesión religiosa. Así lo ha recordado el Tribunal de Grenoble, el 31 de diciembre de 1991: el Ayuntamiento puede reservar en su plan urbanístico un espacio dedicado a la construcción de un templo con la consideración de interés general, siempre que la financiación corra a cargo del constructor ${ }^{21}$.

La Ley de 1905, en su art. 4, preveía la constitución de asociaciones de culto, éstas no pueden recibir subvenciones, sus recursos deben provenir de los fieles. Esta legislación se aplicó a la comunidad protestante y a la judía; sin embargo la iglesia católica no se constituyó en asociación de culto. Después de un largo proceso de negociación se restablecieron las relaciones diplomáticas con la Santa Sede. Se alcanzó el compromiso de la creación de asociaciones de culto diocesanas, establecidas en todas las diócesis entre 1924 y 1927 y en vigor hasta el día de hoy. Los edificios anteriores a este acuerdo (Dictamen del Consejo, del 13 de diciembre de 1923) pertenecen al estado o a los municipios que están a cargo de su mantenimiento; en cambio, a partir de 1924, las asociaciones diocesanas se encargan de la construcción y del mantenimiento de los lugares de culto.

La Ley de Asociaciones de 1901 permitió el desarrollo de multitud de entes con fines caritativos o educativos, que no tienen como fin exclusivo el culto. A esta categoría se suelen acoger los musulmanes, pues la presencia de las escuelas coránicas justifica la calificación cultural lo cual no impide que a su lado funcione una mezquita regida por la misma asociación. En 2003 se creó el Consejo Francés del Culto Musulmán. La representación regional y nacional en el seno de dicho Consejo guarda relación directa con el número de lugares de culto, que en el censo más reciente asciende

2009.state.gov/g/drl/rls/irf/2008/index.htm ; ultima consulta, 15$\mathrm{V}-11$.

18 PARLATO, V., "Uno Stato confessionista degli anni'80: la Grecia”, en Las relaciones entre la Iglesia y el

Estado, en Estudios en memoria del profesor Pedro Lombardía, Madrid, Universidad Complutense, 1989, p.

613.

19 AYUDA A LA IGLESIA NECESITADA, "Grecia», Informe 2008 sobre Libertad Religiosa en el Mundo, http://www.ain-es.org/; última consulta, 15-V-11)

${ }^{20}$ Se pueden citar otros países como: Irlanda, vid. CASEY, J., Legal status of minority churches and religious communities in Ireland, en The Legal Status of religious minorities in the countries of the european union, Milano, Giuffrè, 1994, p. 173 ss. También el caso de Holanda, vid. VAN BIJSTERVELD, S., "Estado e Iglesia en los Países Bajos”, En ROBBERS G., (ed.), Estado (...) Ob. cit., p.219 ss.

${ }^{21}$ Cfr. BASDEVANT- GAUDEMET, B., "Estado e Iglesia en Francia” En Ibidem, p.123. 
a 2.147 para todo el territorio nacional. Este reconocimiento también se tradujo en un mayor número de permisos de edificación, más adelante multiplicado en virtud del decreto nacional de abril de 2006 sobre lugares de culto, que facilitó la aplicación de la enfiteusis, en virtud de ésta, el estado cede terrenos por largo tiempo a cambio del pago anual de un modesto canon y de la obligación de gestionarlos ${ }^{22}$.

\subsection{Irlanda ${ }^{23}$}

El art. 44 de la constitución de la república de Irlanda se titula «Religión». En él, el Estado reconoce que debe homenaje de culto público a Dios Todopoderoso, cuyo nombre reverenciará, «respetando y honrando la religión». A continuación, se garantiza a todos los ciudadanos la libertad de conciencia y la libertad de profesar y practicar la propia religión, a condición de que respeten el orden público y la buena moral. Todas las confesiones tienen derecho a gestionar sus asuntos y propiedades, y a comprar y mantener centros educativos y caritativos. El texto no menciona ninguna religión de Estado y prohíbe dar un trato de favor a una religión frente a las demás, al igual que la discriminación religiosa en las escuelas.

El Estado no financia el mantenimiento (ni la creación) de los edificios de las iglesias, sería inconstitucional según el Art. 44.2.2 24 . Esto no impide que puedan estar exentas de tasas locales. Todas las iglesias y grupos religiosos tienen la misma posición, ninguna es reconocida oficialmente $y$ se constituyen como asociaciones voluntarias. Las iglesias y grupos religiosos no adquieren personalidad jurídica de modo automático, su estatuto legal es de asociaciones sin capacidad jurídica. La propiedad de la iglesia se atribuye a un fideicomisio. La Iglesia católica creó para este fin un Representative Church Body ${ }^{25}$, puede demandar y ser demandado respecto al patrimonio a él confiado. La construcción ex novo de una iglesia, escuela hospital está sujeta al Derecho ordinario y requiere licencia de construcción ${ }^{26}$. Por otra parte los edificios históricos

\footnotetext{
${ }^{22}$ Este proceso es recogido en el informe del Departamento de Estado: "The proposed reform would allow for associations of worship to integrate activities such as social events and book selling, thereby "enlarging the social presence" of such groups. The report proposals support Sarkozy's assertion in 2002 that the state should encourage a public form of Islam, moderated by social recognition and open practice» (U.S. DEPARTAMENT OF STATE, «Francia», 2008 Report on International Religious Freedom, op. cit., ultima consulta: $15-\mathrm{V}-11$ )

${ }^{23}$ CASEY, J., "Legal status of minority churches and religious communities in Ireland", en The Legal Status

(...) Ob. cit., p. 173

${ }^{24}$ Art. 44.2.20 «The State guarantees notto endow any religion»
}

deben estar inventariados y están sometidos a la National Monuments Acts.

\section{EL SISTEMA DE COOPERACIÓN}

\subsection{Alemania ${ }^{27}$}

La Ley Fundamental de Bonn garantiza la libertad religiosa en el art. 4.2. Además, el art. 140 incorpora los arts. 136-141 de la constitución de Weimar. Por otra parte, las constituciones de los estados federales afirman la separación de la iglesia y del estado y establecen un sistema de cooperación entre ambas instituciones para proteger los intereses de los ciudadanos. Así, la República Federal de Alemania y los Lander han estipulado numerosos concordatos y acuerdos con las iglesias fundados en los principios de neutralidad, tolerancia y paridad.

Se confiere a las comunidades religiosas el estatus de corporaciones de Derecho Público (art. 137. 2 de la constitución de Weimar). Las demás confesiones adquieren la capacidad jurídica según el Derecho Civil, pero, en virtud de la libertad religiosa, debe ser tenida en cuenta su organización interna donde sea necesario ${ }^{28}$.

Para que un edificio se convierta en un lugar de culto debe ser afectado (Widmung) según el derecho de cada confesión. La Iglesia Católica, a tenor del c. 1217 del Código de Derecho Canónico, lo hace por medio de la consagración o de la bendición. La Iglesia Luterana mediante un servicio previo (Gottesdeienst). Los edificios de culto son propiedad de las confesiones y asumen su mantenimiento ${ }^{29}$. El art. 138 de la constitución de Weimar garantiza las subvenciones de los estados federales a las iglesias. Esta obligación abarca no sólo el mantenimiento sino también la construcción de nuevos lugares de culto con el único límite del principio de necesidad. Es decir, las necesidades son más que las posibilidades.

El Tribunal Constitucional de Baviera interpretó que según el art. 107 de la constitución del estado de Baviera, el derecho de la libertad religiosa garantiza

\footnotetext{
${ }^{25}$ Se instituyó por el Privilegio Real del 15 de Octubre de 1870. Irish church Act de 1869.

${ }^{26}$ CASEY, J., "Estado e Iglesia en Irlanda”, en En ROBBERS G., (ed.), Estado (...) Ob. cit., p. 157.

${ }^{27}$ Otro sistema de cooperación es el italiano, sobre él se puede consultar: ASTORRI, R., Les lieux de culte dans le droit Italien, en FLORES-LONJOU M.; MESSNER F., (eds.), Les lieux de culte en France et en Europe, Leuven, Dudley, MA: Peeters 2007, p. 196.

${ }^{28}$ Cfr. ROBBERS, G., "Estado e Iglesia en la República Federal de Alemania", En ROBBERS G., (ed.), Estado (...) Ob. cit., Ob. cit., p. 61. 29 PUZA, R., "Les lieux de culte en Allemagne", en FLORES-LONJOU M.; MESSNER F., (eds.), Les lieux (..) Ob. cit., p. 136.
} 
también el derecho de construcción de edificios consagrados al ejercicio del culto ${ }^{30}$. El estado de Baviera considera, por tanto, que la libertad religiosa supone que las comunidades religiosas tienen derecho a construir edificios consagrados para ejercer en ellos el culto. Las comunidades religiosas constituidas en corporaciones, según el derecho público y el resto conforme al Derecho Privado.

\subsection{España}

La Constitución de 1978 consagra la igualdad de todos los españoles ante la ley, «sin discriminación alguna por razón de nacimiento, raza, sexo, religión, opinión o cualquier otra condición o circunstancia personal o social». En concreto, especifica que "se garantiza la libertad ideológica, religiosa y de culto de los individuos y las comunidades sin más limitación [...] que la necesaria para el mantenimiento del orden público protegido por la Ley». Además, en el artículo 16 dispone que ninguna confesión tenga carácter estatal, si bien «los poderes públicos tendrán en cuenta las creencias religiosas de la sociedad española y mantendrán las consiguientes relaciones de cooperación con la Iglesia católica y las demás confesiones».

El Art. 16.3 tiene su fundamento en la acción promocional de los derechos fundamentales por parte del Estado social, por lo que es una proyección del Art. 9.2 de la $\mathrm{CE}^{31}$. El principio de cooperación tiene su fundamento en la valoración positiva del ejercicio de la libertad religiosa pero encuentra su límite en los principios de igualdad y laicidad del Estado ${ }^{32}$. No es admisible que el Estado discrimine a sus ciudadanos por motivos religiosos. La cooperación con las confesiones debe hacerse de tal manera que queden salvaguardadas la libertad y la igualdad de los demás grupos religiosos y de los no creyentes ${ }^{33}$. El principio de laicidad está al servicio del principio de igualdad en la libertad y su fundamento se encentra en la máxima realización del ejercicio de la libertad de conciencia. El Estado está obligado a promover las condiciones para que la libertad e igualdad ideológica sean reales y efectivas, sin vulnerar el principio de laicidad. Como

\footnotetext{
30 BayVGH. BayVBL, 1997, 144.

${ }^{31}$ Así lo confirmó la sentencia del Tribunal Constitucional 46/2001, del 15 de febrero.

32 RODRÍGUEZ GARCÍA, J.A., "A vueltas con Urbanismo y Confesiones Religiosas", en MORENO REBATO, M., (coord.), Estudios jurídicos de derecho urbanístico y medioambiental: librohomenaje al profesor Joaquín $M^{\underline{a}}$ Peñarrubia Iza, Madrid, Montecorvo: Universidad Rey Juan Carlos, 2007, pp. 151-183.

33 PRIETO SANCHIS, L., Principios constitucionales del Derecho Eclesiástico español, Madrid, 2004, p.46.

${ }^{34}$ RODRÍGUEZ GARCÍA, J.A., Libertad religiosa y confesiones. EI régimen jurídico de los lugares de culto, Madrid, Boletín Oficial del
}

instrumento de esta obligación se configura el principio de cooperación.

La Ley Orgánica de libertad religiosa, del 2 de Julio de 1980, en el Art. 2 afirma: «La libertad religiosa y de culto garantizada por la Constitución reconoce el derecho de las Iglesias, confesiones y comunidades religiosas a crear lugares de culto o de reunión para las prácticas religiosas». Las Comunidades Autónomas son competentes en materia urbanística, pueden reservar espacios para los lugares de culto en los planes urbanísticos.

El Tribunal Constitucional distingue entre la cooperación obligada y la posible. La primera es la necesaria para hacer real y efectiva la libertad religiosa, la segunda es la que contribuye a facilitar el ejercicio de la libertad religiosa con el límite de la igualdad y laicidad.

Para algunos autores los lugares de culto no se incluyen dentro del concepto de servicios pues las funciones de culto, en un Estado laico, no son llevadas a cabo por la Administración pública. Los lugares de culto no son bienes afectos a un uso público, pues los poderes públicos no tienen la obligación de establecerlos ni de costearlos. No se puede confundir el uso público con el carácter abierto al público que pretende algunos lugares de culto ${ }^{34}$. En cambio para otros, la cesión de bienes inmuebles a parroquias para dedicarla al culto, son entidades de interés público pues redundan en beneficio de los habitantes del término; además, la promoción de fines religiosos es una garantía del derecho fundamental de la libertad religiosa; igual que si se cediese bienes a cualquier otra institución ${ }^{35}$.

No hay restricciones legales para construir nuevas centros de culto. El establecimiento de lugares culto forma parte del contenido esencial del derecho fundamental de libertad religiosa, es un derecho que no está sometido a ningún tipo de autorización discrecional por parte de la Administración ${ }^{36}$. El Tribunal Supremo considera que la autorización administrativa de apertura puede suponer una cierta limitación al derecho de la libertad religiosa ${ }^{37}$. Esta línea jurisprudencial ha sido criticada porque exigir ciertas

Estado : Centro de Estudios Políticos y Constitucionales, 2000, pp. 186-187.

35 GONZALEZ BUSTOS, M., Los bienes de propios: Patrimono local y administración, Madrid, Pons, 1998, p. 234.

36 RODRÍGUEZ BLANCO, M., "Manifestaciones del Derecho fundamental de libertad religiosa", en CORSINO ÁLVAREZ, A. ; RODRÍGUEZ, M., (coor), La libertad religiosa en España : XXV años de vigencia de la Ley orgánica 7/1980, de 5 de julio : (comentarios a su articulado), Granada, Comares, 2006, p.85.

${ }^{37}$ Sentencia del 24 de Junio 1988, 4724. 
garantías,-sanitarias, o de seguridad- no supone una restricción desproporcionada de la libertad religiosa. Por otro lado, tales licencias tienen carácter reglado de tal forma que todo sujeto tiene derecho a obtenerlas si cumple con los requisitos legales establecidos al efecto $^{38}$

Para abrir o construir un lugar de culto se ha de obtener el permiso de construcción según las normas urbanísticas, que establecen los distintos usos del suelo urbano $^{39}$. Las iglesias están exentas de impuestos en el caso de la Iglesia católica y también los lugares de culto de las confesiones con Acuerdo (Protestantes, Judíos e Islámicos) ${ }^{40}$. Las confesiones inscritas se benefician de la aplicación de la normativa específica del Derecho eclesiásticos. Los demás grupos religiosos no inscritos o que no tienen cabida en la LOLR se pueden acoger al derecho común de asociaciones.

A escala local, el Gobierno de Cataluña ha preparado para los lugares de culto un proyecto de ley cuyo fin es impedir la celebración de cualquier rito religioso sin permiso previo, adjudicando a cada municipio la facultad de conceder licencias a las Iglesias. De aprobarse esta ley, incluso un encuentro de oración precisaría de un permiso especial, otorgado o no a discreción de las autoridades locales. Según el Gobierno de la Generalitat (Gobierno autonómico catalán), la propuesta surge de la necesidad de restringir la proliferación indiscriminada de mezquitas y templos de otras confesiones minoritarias. Sin embargo, su aplicación «afecta de lleno a la Iglesia católica», pues, en la práctica, «no se podrá celebrar misa ni reunirse para hablar de religión sin una licencia municipal, ni en la ermita más pequeña ni en la mayor catedral». Los lugares de culto ubicados en hospitales, sanatorios, prisiones y lugares que pertenezcan al patrimonio artístico del país podrán quedar exentos de la obligación de solicitar un permiso ${ }^{41}$.

\section{Conclusiones}

Después de exponer los tres principales sistemas de relaciones entre los Estados y las distintas iglesias, podemos afirmar que la libertad religiosa puede estar garantizada de formas diversas. Tanto la Confesionalidad, como la Separación y la Cooperación permiten el libre ejercicio de la libertad religiosa, al menos desde el punto de vista individual. Otra cosa bien distinta, es en el plano colectivo, cuando las iglesias, o las comunidades quieren ejercer colectivamente sus derechos. En el caso de la confesionalidad, las iglesias no oficiales no se encuentran en el mismo plano de igualdad con la iglesia oficial. En el sistema de separación, todas las iglesias o comunidades se reducen a meras asociaciones, obviando la especificidad del derecho de la libertad religiosa. Por último, el sistema de cooperación garantiza la igualdad de todas las iglesias y comunidades, sin olvidar que la libertad religiosa no es meramente individual sino que también es colectiva. Con lo que se resuelve los problemas que plantean las iglesias nacionales, y el sistema de separación.

Siempre es mejor que los Estados cooperen con todas las instituciones para hacer que todos los derechos no sean meramente nominales sino reales y efectivos, tanto a nivel individual como colectivamente.

BLANCO, M., Los convenios entre las Administraciones Públicas y las confesiones religiosas, Pamplona, Navarra Gráfica Ediciones, 2003, pp. 125-132.

${ }^{40}$ Sobre el régimen fiscal se puede consultar: RODRÍGUEZ BLANCO, M., "El estatuto jurídico-tributario de los lugares de culto", en Anuario de Derecho Eclesiástico del Estado, 16 (2000), pp. 509-607. ${ }^{41}$ RODRíGUEZ GARCÍA, J. A., "A vueltas (...)” , en Ob. cit., p.173.
38 RODRIGUEZ BLANCO, M., "Les lieux de culte en droit espagnol”, En FLORES-LONJOU M.; MESSNER F., (eds.), Les lieux (...) Ob. cit., p. 196.

39 Las Comunidades Autónomas son competentes en materia urbanística. Las leyes autonómicas suelen reservar terrenos para los servicios religiosos, como equipamiento de interés público y social en los planes urbanísticos. Es habitual, en la fase de ejecución, la cesión de terreno publico para la construcción de lugares de culto. El ente religioso se compromete a mantener la afectación del inmueble para el culto público. Cfr. RODRíGUEZ 